\title{
A Model For Teaching Integration Of Business Disciplines To Freshman Business Majors
}

Michael Marsh (Email: mtmars@ship.edu), Shippensburg University of Pennsylvania Susan Stone (Email: srston@ ship.edu), Shippensburg University of Pennsylvania

\begin{abstract}
The John L. Grove College of Business recently completed major revisions to the core curriculum as part of AACSB recertification efforts. A significant omission in the "old" curriculum came to light during focus groups and surveys of students. They revealed that the curriculum that had existed virtually unchanged for twenty years had no provisions for giving students an overview of how coursework fit together. In addition, students had virtually no exposure to finance, management, or marketing until their junior year, even though many had declared one of these as their major. A solution agreed upon by the business faculty was to incorporate a freshman business integration experience course, Foundations in Business Administration, into the new curriculum. The course is designed to expose students to various disciplines in business and present the basics of how these disciplines interact in businesses. In addition to the focus on business disciplines, the course includes numerous activities designed to help students develop a better understanding of how their goals and interests can be integrated into the process of planning academic and career goals with emphasis on relating their academic and extracurricular activities to those career goals. The Freshman Business Experience, now referred to as the Business Integration Experience, has been in the curriculum for one academic year. This paper provides details about the development and implementation of the initiative, lessons learned from the first year's experience, and preliminary assessments of the program's effectiveness.
\end{abstract}

\section{Introduction}

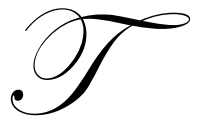

he John L. Grove College of Business has recently implemented a new core curriculum (Appendix 1). One of the driving mandates received from the business community was to provide enough flexibility in the core requirements to allow students to be prepared in depth in more than one major area. (Holoviak and Marsh, 2003) In addition, focus groups and surveys of students revealed that students were dissatisfied with several very specific parts of their programs. One key element of that dissatisfaction was not having any overview of how their coursework fit together. Another source of dissatisfaction was not having adequate exposure to all areas of business before solidifying their decisions regarding their majors. For example, students had no exposure to finance, management, or marketing until their junior year yet are required to declare a major during their sophomore year.

In response to these concerns, the new business core curriculum was designed to include a Foundations of Business Administration (FBA) course. Students who have formally declared business as their major course of study under the new core are required to participate in this course. Expected enrollment for business majors is approximately 350 per year but the number of students in the course exceeds that as many transfer students and undeclared students also elect to participate and are accommodated. The Department of Management and Marketing played the pivotal role in development of this program. The marketing faculty committed a full-time faculty member and a graduate assistant to develop and implement the proposal, reflecting the College's responsiveness and commitment to improving the academic experiences of its students. 


\section{Supporting the Initiative}

The course is designed so that students are not only exposed to the various disciplines in business, but also are guided through a personal assessment that aids them in identifying personal goals, developing direction for choice of a major, and setting forth an overall plan for how to put together key university study and student life variables. This guidance is considered essential in supporting the mission of the College but requires extraordinary commitment to providing faculty resources as well as exceptional commitment from those faculty members electing to participate.

Guiding students in this endeavor has proven to be challenging and includes the following:

1. Coordination and application of inputs from the College of Business disciplines and across the university. To support this, professors and other speakers including students and alumni are recruited and their materials processed for student access. A senior professor from each discipline in the College is given an opportunity to present information about their discipline including course requirements, careers, and internships.

2. Various types of assignments, such as reading and attending presentations, and attendant writing assignments are integral to the course. All writing assignments are evaluated and feedback provided. The amount of time required of the single faculty teaching the course and the one graduate assistant is of particular note. For example, during the first two weeks in a semester students are assigned to write briefs of two chapters, write their reflections regarding the outcomes of their personal assessment, and develop a first draft of their goals for five years, resulting in a minimum of 720 pages that are evaluated and feedback provided.

3. Student interaction is a key element in the course. Students are encouraged, and at times, required, to schedule personal sessions for feedback regarding their assessments, formalize their study plans, show progress toward deciding on a major, and develop ideas regarding how to choose general education courses, electives, and student life opportunities. Each student in the course signs up for 15-minute appointments with the course professor. Consider, again, the time element for faculty. Meeting with each student of the approximately 180 students in the course, one-on-one for 15 minutes, takes approximately 45 hours.

\section{Elements of the Initiative}

One goal of this foundation course is to help students develop a solid base upon which to build a process of making good choices. (Freshman Year Experience, 1989) It is intended to provide students with the information, tools, and guidance they need to develop a habit of making independent decisions regarding, precisely, how they will allot their time while at the university in order to meet their personal goals. (A course syllabus is included in Appendix 2.) In addition to providing information about majors and careers, the program is intended to help students see how various elements of their university experience fit together beginning the process of integration. Arguably, the most valuable feature in the course to help facilitate this is the development of the four-year strategic study plan that students create.

The first thing the students do in the course is take the Self-Directed Search (Holland) personal career assessment. Students meet with the course professor individually to discuss the results of their assessments. They are encouraged to meet with their advisors, also, to discuss their assessment results. A journal (also required of students) entry reflecting on the relevance of the findings of the assessment and goals that students can identify based on these reflections then becomes a part of their strategic plan.

Students are next exposed to the University-wide general education program. Specific course requirements are addressed and particular attention is paid to the benefits of studying the categories of knowledge. This has proven to be a difficult, but enlightening, experience for both students and faculty in the College of Business. 
Students are then presented with the details of the College of Business core and major requirements. Speakers from each business discipline give overviews of their fields and discuss opportunities within each major. This includes ideas about appropriate minors, double majors, and elective choices that could benefit students in developing strength in their chosen fields. Some focus is placed on aspects of study and extra-curricular experiences that would make them more competitive when they are ready enter the job market. A highlight of the course is discussions with current students and recent graduates. These students speak about their majors, internships experiences and their value, clubs students can join to enhance their understanding of their disciplines, and their marketability. Particularly lively banter regarding basic "survival" in the College of Business is routinely experienced. Students are also required to attend a case presentation given by students in the capstone courses. Students have related getting two distinct benefits. They get a good feel for the level of expertise they will likely attain during their four years, which helps build their confidence and alleviates some of their concerns about their current knowledge and skill levels. They also are able to see how elements of a particular program of study fit together in producing a comprehensive analysis of a business situation.

Students use the information and tools gathered in the above experiences to develop a four-year study plan, which includes specific course choices for all four years. Students who are not yet ready to declare a major are asked to choose one of their most likely possibilities to use so that they can understand how to develop the plan and make changes in the future. Each student is required to meet with the course professor to be sure their plan is on track. They are also required to meet with their advisor to discuss and sign their completed study plan. This study plan and the process of developing it give students something concrete to take away from the course. A typical study plan includes a statement of career goals, assessment results, and a plan outlining a schedule of specific courses to be taken. It is stressed that their choices may change but they leave the course with the understanding that they are not only ultimately responsible for making those choices but also have an increased level of confidence on their capabilities of doing so.

\section{Sustaining the Initiative}

A key concern is sustaining the initiative. One of the primary difficulties will surely be maintaining adequate, dedicated resources. The faculty workload for the professor teaching this course is time intensive. Resolving this issue will require working with colleagues inside and outside the College of Business to build relationships, engender support, and garner resources. As assessment of the value added of the course is completed there may be additional sources of faculty resources. (Solid Foundations, 1999)

Another area that needs to be monitored is the change in the culture of advising that having better informed students will have. Students are likely to be more demanding of advisor time to develop career paths, for example, and less interested in scheduling issues. As the literature in this area suggests not all professors understand the difference between scheduling and advising, nor is there agreement as to what constitutes a reasonable amount of time faculty should spend on advisement. It may not be possible to change these ideas directly, however, students may be able to precipitate these changes as the Foundations of Business Administration creates better-informed, more demanding students. They will have been exposed to advisement that deals with both details and the big picture of their university experience, not just scheduling. The study plan assignments supplant the bulk of the time needed for scheduling advice in the freshman year. Students are required to meet with their advisors, thus establishing a relationship with advisors early in students' undergraduate studies.

Another area that will be equally interesting to follow is the extent to which students really appreciate the benefits of this program. As is often the case, people who have privilege may not understand its value. People who do not have the privilege are keenly aware of the value of the privilege. Preliminary focus groups have already acknowledged different perspectives. Upperclassmen that did not have the opportunity to participate in the program are keenly aware of how it could have helped them. Freshmen, especially early in the course, have little appreciation for the program and frequently regard the assignments as "busy work" with little obvious value. Student feedback has indicated students perceived the study plan assignments as most useful. 


\section{Measuring the Effectiveness of the Initiative}

The College of Business is committed to continuous improvement of its curriculum to reflect stated needs of the regional business community, alumni, faculty, and students. Addressing this mandate requires assessment. Assessment provides insights into what benefits the program is providing to students and how it is addressing the mission of the College of Business. It is also expected that the content and assessment of this program will provide positive, documentable, and useful revelations with regard to the role of the program in improved advisement and to improvement in satisfaction measures for students overall.

A baseline study was done during the 2001-2002 school year, a year before the FBE was first implemented. Continuing assessment is providing information about the program's value added in terms of knowledge about disciplines, careers, and selected activities and opportunities. Focus groups are being conducted with sophomores (who have and have not participated in the program). This will provide information about the program's contributions to the advisement process. Faculty, administrators, and support staff are being surveyed to gather insights into their views regarding the effectiveness of the program. Samples of the selected instruments may be found in the Appendices. Student evaluations and personal interviews are also being used.

Although this is a new initiative, some early assessment results are available but the effectiveness of the program will be best measured over at least a five-year period. (Davis and Lee, 1994) This program is being evaluated on the following criteria: improved student performance, retention, four-year graduation rates, and student satisfaction with advisement. We will also investigate its impact on timing of choosing a major and major switching. It will take at least five years for the impact of students having an overall plan of action to be felt among individual advisors.

A questionnaire was developed and administered to students both before and after the course. The course has only been in existence for one academic year but the preliminary results are encouraging. Significant improvement in student knowledge of major and careers was evident. This is especially true of less well known disciplines such as information systems, supply chain management, and e-business. Aggregated and averaged responses for approximately 150 students from the fall, 2002 semester are shown in Figures 1 and 2.

\section{Figure 1}

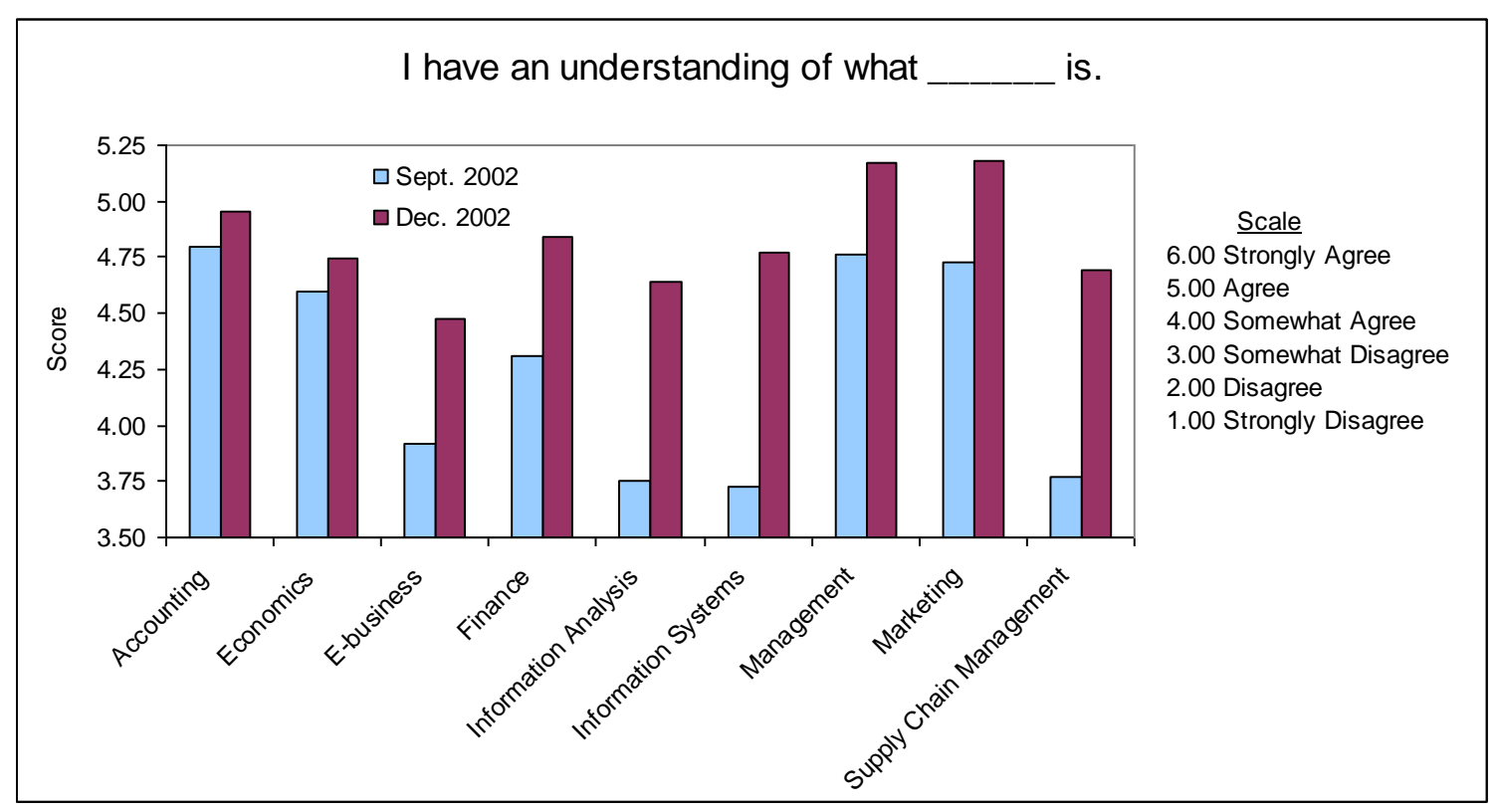


Figure 2

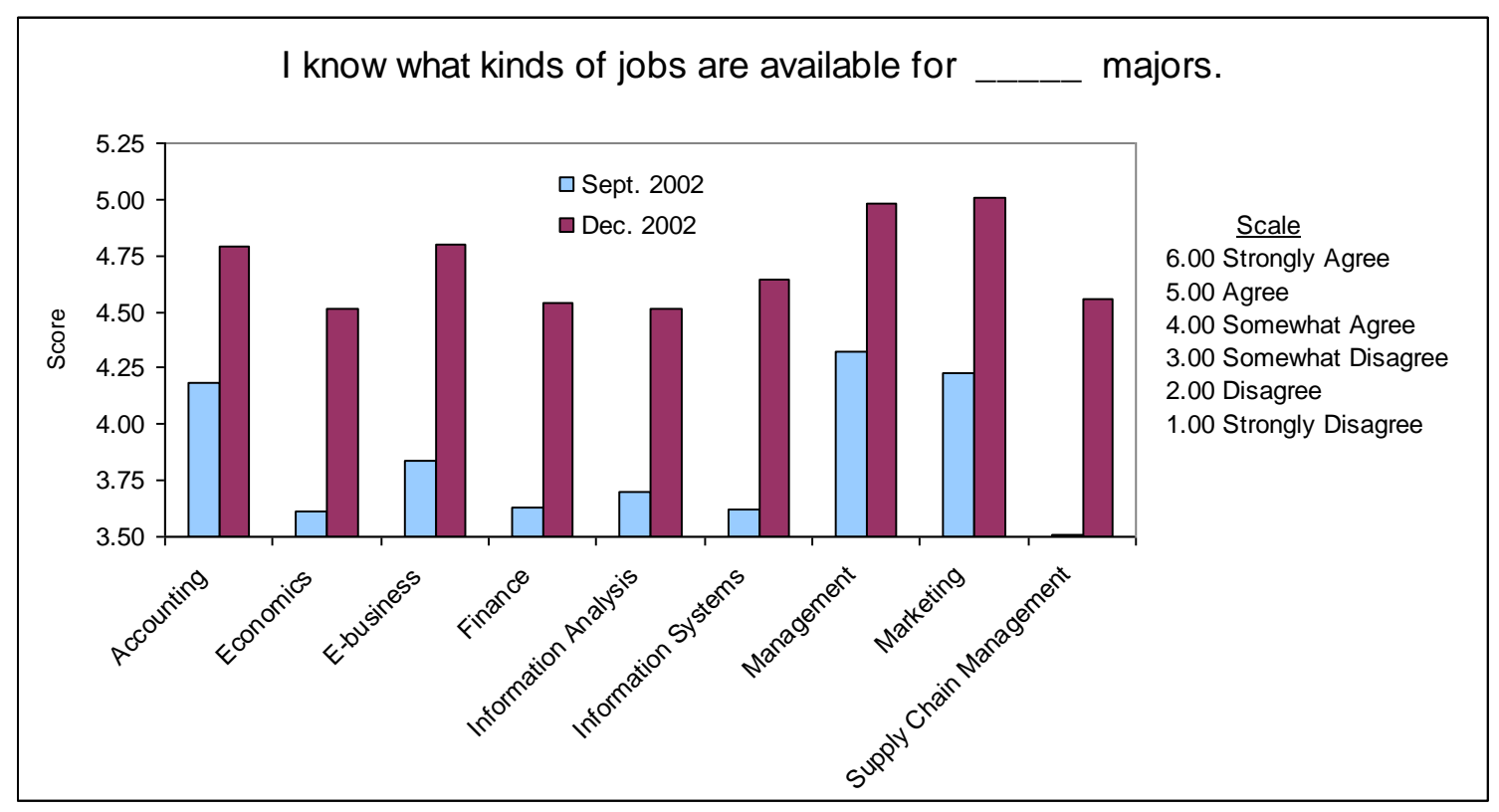

Despite the significant gains that occurred in students' apparent knowledge about disciplines and majors, they were not as successful applying the knowledge to their own situation. Table 1 shows only slight improvement was gained during the course in students' confidence to select a major or career. It should be noted, however, most students had fairly definite ideas even before the FBA course. One anomaly is that their confidence in having enough knowledge to select a major by the end of the freshman years decreased slightly. Anecdotal evidence explains this in that original plans were reevaluated as students gained more information about their original choice or were exposed to more choices.

Table 1

\begin{tabular}{|l|c|c|}
\hline & Sept. 2002 & Dec. 2002 \\
\hline I have a clear idea of my skills, interests, and abilities. & 4.77 & 4.92 \\
\hline I have a clear idea of my career goals. & 4.72 & 4.81 \\
\hline I understand how my skills, interests, and abilities match my career goals. & 4.61 & 4.78 \\
\hline I have a clear idea of what major I want. & 4.61 & 4.75 \\
\hline I have a clear idea of what electives I may want to take. & 3.99 & 4.68 \\
\hline I expect to know more about what to major in by the end of my freshman year. & 5.22 & 5.03 \\
\hline
\end{tabular}

Scoring key: 6 - Strongly Agree; 5 - Agree; 4 - Somewhat Agree; 3 - Somewhat Disagree; 2 - Disagree; 1 -

Strongly Disagree

\section{Lessons Learned}

Feedback from students who have completed the course and the experiences with the course from faculty have highlighted aspects of the course that are working well and as intended as well as others that have not provided the anticipated results. 
The perception of course content by students is quite different from the actual, or at least intended, objectives. Students perceive it as simply a course to help them choose a major while the primary intent is to provide information about how the various disciplines of the business world are integrated. One attempt to change students' perceptions has been to change the program's name. The program, originally titled, "Freshman Business Experience" was changed to "Business Integration Experience" this year. The name change also made it clearer that the course is not just for freshman, but also includes internal and external transfers. It should be noted that the course title remains, "Foundations of Business Administration."

A typical class size is approximately 90 students, about three times the size of typical business classes at Shippensburg University. Presentations are typically a lecture format with little class involvement or discussion. More small group work is needed to enliven the class meetings and get students more involved with the course material. (Soldner, et al, 1999)

The program is resource intensive. This issue needs to be addressed to ensure the long term viability of the program. One step taken in the second year has been changes in the development of study plans. During the first year of the program, the course professor accepted primary responsibility for working with students, one-on-one, to assist them with developing their study plans. This year, the primary responsibility shifts to the students' assigned academic (faculty) advisor with FBA professor acting as the secondary contact.

Individual disciplines in the College need to develop better marketing, information, and educational resources. The information students have about various disciplines is frequently flawed and this program presents the ideal forum to provide the latest factual information.

The program is designed to provide opportunities for working professionals to become involved. The College will be taking a more active leadership role in contacting individuals and organizations whose involvement with the program will be mutually beneficial. (Kenworthy, 1996) For example, the regional supply chain/logistics professionals will be sponsoring "career night" sessions each semester and these can easily be integrated as activities towards meeting course requirements.

The decision to use a pass/fail format as the course grading criteria is being validated. Students who complete a required number of activities and turn in the required, "acceptably completed" assignments receive a passing grade. This grading option is appropriate for providing an appropriate level of assessment and ensuring satisfactory completion of assignments while not adding to the burden of having to provide specific quantitative feedback on assignments. (Hyers and Joslin, 1998) There are no exams, per se, in the course.

\section{Conclusions}

The Foundation of Business Administration course has already proven its value to students. Since the program has been in existence only one year, analysis of the preliminary objective assessment data has not yet been completed. Anecdotal evidence and informal subjective evaluation indicate that the program is successful in meeting many of its objectives. On a personal level, current year sophomores who have completed the course are demonstrating increased levels of knowledge regarding course selection, choice of major, and career aspiration. In specific curriculum matters, the same students appear to be more comfortable with the interrelationship among concepts presented in first and second year business courses, accounting, economics, information technology, and data analysis, for example. Data from student experiences will continued to be gathered for the foreseeable future and course will necessarily continue to evolve to better meet the needs of the students. It is anticipated that the Business Integration Experience Initiative will remain one of the primary building blocks upon which students in the John L. Grove College of Business build their academic and professional future. 


\section{References}

1. Davis, U.M. and J.A. Lee (1994), "An Evaluation of the University of North Carolina at Charlotte Freshman Seminar", Journal of College Student Development, (35), 491-2.

2. Hyers, A.D., and M.N. Joslin (1998) "The First Year Seminar as a Predictor of Academic Achievement and Persistence", Journal of Freshman Year Experience, (10), 7-30.

3. Holoviak, S. and M.T. Marsh (2003), "An Experience with a Faculty-Driven Approach to Business Curriculum Revision and Faculty Reorganization”, Journal of Business \& Economic Research, (1/7), 97 104.

4. Kenworthy, A.L. (1996), "Linking Business Education, Campus Culture and Community", Journal of Business Ethics, (15/1), 121-131.

5. Soldner, L, Y. Lee, and P. Duby (1999), "Welcome to the Block: Developing Freshman Learning Communities That Work", Journal of College Student Retention, (1/2), 115-129.

6. Solid foundations: Building Success for First-Year Seminars Through Instructor Training and Development, Monograph series, number 29, Hunter, M.S. and T.L. Skipper (Eds.), 1999.

7. The Freshman Year Experience, San Francisco: Jossey-Bass, Upcraft, M.L. and J.N. Gardner (Eds.), (1989). 
Appendix 1

John L. Grove College of Business Core Curriculum

Effective September, 2002

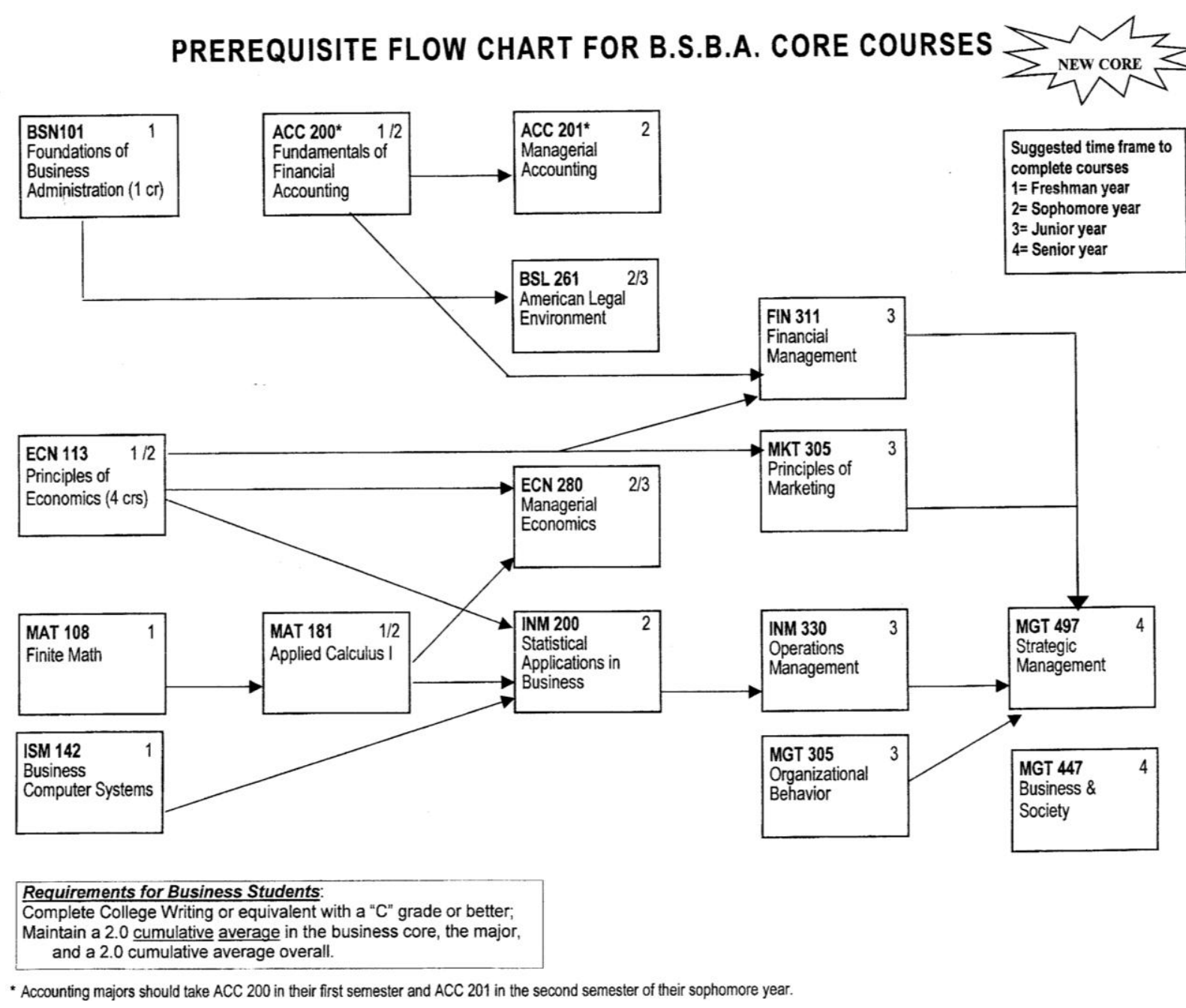




\section{Appendix 2 \\ Business Integration Experience \\ BSN101 Foundations in Business Administration \\ Fall 2003 Dr. Susan Stone}

\section{Catalogue Course Description:}

Foundation course for all majors in the College of Business. Establishes platform for student understanding of functional areas in business and how they work in concert for the benefit of the organization. Students will gain meaningful information and tools so that they may make informed choices with respect to their educational experiences and pursuit of a career in business. (1 s.h.)

Text:

Kuiper, Shirley (Editor). Transition into Business.

Self-Directed Search Booklets

\section{Objectives:}

1. To provide students with an opportunity to investigate their goals, interests, skills, and abilities in order that they may be able to begin to make informed choices with regard to how they will meet their personal goals through a meaningful university experience.

2. To begin the integration process by providing a platform on which to build student understanding of what different functional areas are in business, how they work in concert for the benefit of the organization, and how this breadth of knowledge will benefit students in working toward their goals.

3. To provide exposure to a breadth of university experiences, both educational and extra-curricular, and to suggest ways in which students can make these experiences work together for them in accomplishing their goals.

4. To provide exposure for students regarding what they will be working toward in terms of possible careers in business.

\section{Course Requirements:}

1. Students will be required to attend class.

2. Students will be required to read the text and complete briefs of chapters.

3. $\quad$ Students will be required to keep a journal discussing selected experiences.

4. Students shall complete a four-year plan that includes personal goals, career goals; and possible pathways for achievement of those goals, including a study plan. Not only will this plan include initial decisions regarding coursework, majors, minors, general education, and free electives; but it will also include plans for developing networking possibilities, internships, special skills, possible club memberships, and extracurricular activities. These elements will be explicitly related to the students' goals.

5. Students will be required to attend a senior strategy presentation, so that they will have a better idea of where the work they are doing is leading.

\section{Course Evaluation:}

This course is being offered Pass/Fail. In order to pass:

- $\quad$ You must attend 12 of the 14 classes. You must attend class on 12/3.

- $\quad$ You must successfully complete a Study Plan, discuss it with your advisor, and have it signed by your advisor.

- $\quad$ You must attend a Management Strategy Presentation and complete a journal entry regarding the case and the presentation.

- You must successfully complete, $85 \%$ of all other assignments.

\section{Office Hours:}

- I want you to be able to talk with me when you need or want to. I have set things up to try to make sure that can happen. 
- $\quad$ My posted office hours are: Tuesday 12-3, Wednesday 2-3, and Thursday 1-2; however, I am here almost all the time and will meet with you by appointment. There are sign-up sheets on my door.

- My office is 219 Grove Hall. My extension is x1697. My e-mail is srston@ship.edu

\section{Class Schedule:}

8/27: Introduction

Course Overview, Computer Intro, Assessment Intro, Journal Intro

Assignment:

- $\quad$ Get into Blackboard (Bb). Look at your study plan template (in Course Documents), try to download it into your documents. Be ready to ask questions about it next session.

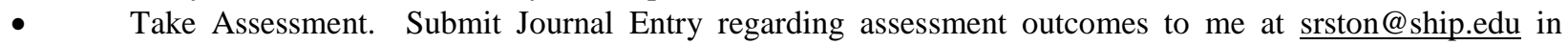
WORD, as an attachment no later that $5 \mathrm{pm}, 8 / 31$. Your name and the name of the assignment must be in the subject line of the e-mail.

- $\quad$ Read Ch. 1. Submit Journal Entry briefing content to me at srston@ ship.edu in WORD, as an attachment no later that $5 \mathrm{pm}$, Sunday, $8 / 31$. Your name and the name of the assignment must be in the subject line of the e-mail.

- I encourage you to set up a time as soon as possible to talk with me. I would like to meet you one-onone and I would like to discuss your assessment results with you. Bring them with you when you come.

9/3: Introduction

Q\&A Computer \& Assessment, Introduce Study Plan (SP)

Assignment:

- Write a rough draft of your GOALS section of your Strategic Study Plan. Focus on where you want to be in five years. Send it to me at srston@ @hip.edu in WORD, as an attachment no later than 5 pm, Sunday, 9/7. Your name and the name of the assignment must be in the subject line of the e-mail.

- $\quad$ Read Chapters 2, 4, and 11. Submit ONE journal entry that briefs all three chapters. Be sure that it is substantive. Submit Journal Entry briefing content to me at srston@ship.edu in WORD, as an attachment no later that $5 \mathrm{pm}$, Sunday, 9/7. Your name and the name of the assignment must be in the subject line of the e-mail.

- $\quad$ Submit a one-page Journal entry discussing a career that interests you. There should be some evidence that you have done some research on this career. Send it to me at srston@ ship.edu in WORD, as an attachment no later that $5 \mathrm{pm}$, Sunday, 9/7. Your name and the name of the assignment must be in the subject line of the e-mail.

9/10: Requirements

College of Business Requirements, Major Requirements, General Education Requirements

Assignment:

- $\quad$ Begin to develop the four-year plan of what courses you will be taking that is part of your strategic study plan. Relate your choices to your goals. You do not need to submit at this time.

9/17: General Education

- $\quad$ Please read Chapter 3: Economics. Submit Journal Entry briefing content to me at srston@ship.edu in WORD, as an attachment no later that $5 \mathrm{pm}$, Sunday, 9/21. Your name and the name of the assignment must be in the subject line of the e-mail.

- $\quad$ Please submit a Journal entry regarding the value of General Education to you. No more than a page. Follow format requirements. Submit to me through e-mail no later than 5 pm, Sunday 9/21.

- $\quad$ You must meet with my graduate assistant, April, or me before 4 pm, 10/21, to discuss the Strategic Study Plan that you have been working on with your advisor. You must have your draft of the plan with you when you come to the meeting including: assessment results; goals; and course and extracurricular choices for 4 years, with their relationship to your goals. You will need to choose a possible major in order to accomplish this task, though you may well not yet have decided to declare that major. Once you know how to go through the process you will be able to change the variables more easily. You will have to meet with your advisor to discuss this plan prior to meeting with April or me. Your advisor must sign the worksheet stating that they worked with you on the plan.

9/24: Student Groups 
10/1: Economics

Speakers from Economics.

Assignment:

- $\quad$ Please read Chapter 5: Accounting. Submit Journal Entry briefing content to me at srston@ship.edu in WORD, as an attachment no later that $5 \mathrm{pm}$, Sunday, 10/5. Your name and the name of the assignment must be in the subject line of the e-mail.

10/8: Accounting

Speakers from Accounting.

Assignment:

- $\quad$ Please read Chapter 6: Information Systems and Quantitative Business Analysis. Submit Journal Entry briefing content to me at srston@ ship.edu in WORD, as an attachment no later that 5 pm, Sunday, 10/12.

Your name and the name of the assignment must be in the subject line of the e-mail.

- $\quad$ Continue Meetings regarding Strategic Study Plan. See Assignment for 9/17.

10/15: Management Information Systems

Speakers from Management Information Systems

Assignment:

- $\quad$ Please refresh your reading regarding Quantitative Business Analysis in Chapter 6 and Read Chapter 8. Submit Journal Entry briefing content of Chapter 8 to me at srston@ ship.edu in WORD, as an attachment no later that $5 \mathrm{pm}$, Sunday, 10/19. Your name and the name of the assignment must be in the subject line of the e-mail.

- $\quad$ Continue Meetings regarding Strategic Study Plan. See Assignment for 9/17.

10/22: Information Management and Analysis (Decision Science)

Speakers from Information Management and Analysis (Decision Science).

Assignment:

- $\quad$ Please Read Chapter 7: Management. Submit Journal Entry briefing content to me at srston@ship.edu in WORD, as an attachment no later that $5 \mathrm{pm}$, Sunday, 10/26. Your name and the name of the assignment must be in the subject line of the e-mail.

- $\quad$ Sign up to visit one Management Strategy Presentation. These sign-up sheets are posted on my door. Note where the presentations will be held. You cannot pass this course without attending one strategy presentation. When you sign up for a time, you must show up. You must be on time. Failure to do so will result in a 50\% deduction. You will be required to read the case before attending, and you will be required to submit a one-page journal entry discussing the case by $5 \mathrm{pm}$ Sunday following the presentation you attended.

10/29: Management

Speakers from Management.

Assignment:

- $\quad$ Please read Chapter 9: Marketing. Submit Journal Entry briefing content to me at srston@ ship.edu in WORD, as an attachment no later that $5 \mathrm{pm}$, Sunday, 11/2. Your name and the name of the assignment must be in the subject line of the e-mail.

- $\quad$ Submit a Journal entry briefing the chapter.

11/5: Marketing

Speakers from Marketing.

Assignment:

- $\quad$ Please read Chapter 10: Finance. Submit Journal Entry briefing content to me at srston@ship.edu in WORD, as an attachment no later that $5 \mathrm{pm}$, Sunday, 11/9. Your name and the name of the assignment must be in the subject line of the e-mail.

11/12: Finance

Speakers from Finance.

11/19: Internships and Careers

Speaker

11/26: Thanksgiving Break

12/3: Mandatory session. Wrap-up.

- $\quad$ Study Plans, signed by your advisor, are due no later than 4:30, 12/3. You cannot pass this course without meeting this requirement. 
Notes 